\section{References}

1 Delange F, Illig R, Rochiccioli P, Brock-Jacobsen B. Progress report 1980 on neonatal thyroid screening in Europe. Acta Paediatr Scand 1981;70: 1-3.

2 Alm J, Larssen A, Zetterstrom R. Congenital hypothyroidism in Sweden. Acta Paediatr Scand 1978;67:1-3.

3 De Jonge GA. Congenital hypothyroidism in the Netherlands. Lancet 1976 ;ii:143.

4 Delange F, Dodion J, Wolter R, et al. Transient hypothyroidism in the newborn infant. $\mathcal{F}$ Pediatr 1978;92:974-6.

${ }^{5}$ Hulse JA, Grant DB, Clayton BE, et al. Population screening for congenital hypothyroidism. Br Med $\mathcal{F} .1980 ; 280: 675-8$.

- Edwards RWH, Hulse JA, Jackson D, Spracklan A, Clayton BE. Programming and running radioimmunoassay in the h-TSH screening procedure using dried blood spots and the NE 1600 Gamma Counter on line to the HP 9815S Calculator. Ann Clin Biochem 1980;17:122-9.

${ }^{7}$ Hulse JA, Jackson D, Grant DB, Byfield PGH, Hoffenberg R. Different measurements of thyroid function in hypothyroid infants diagnosed by screening. Acta Paediatr Scand 1979;277,suppl:21-5.
${ }^{8}$ Pyle SI, Waterhouse AM, Greulich WW. A radiographic standard of reference for the growing hand and wrist. Chicago: Case Western Reserve University, 1971 .

9 Hulse JA. Two children with cerebral gigantism and congenital primary hypothyroidism. Dev Med Child Neurol 1981 ;23:242-6.

10 Newborn Committee of the European Thyroid Association. Neonatal screening for congenital hypothyroidism in Europe. Acta Endocrinol (Kbh) 1979;90,suppl 223:1-29.

11 Kaplan M, Kauli R, Lubin E, Grunebaum M, Laron Z. Ectopic thyroid gland: a clinical study of 30 cases and review. $\mathcal{F}$ Pediatr 1978;92:205-9.

12 Schultz RM, Glassman MS, MacGillivray MH. Elevated threshold for thyrotropin suppression in congenital hypothyroidism. Am f Dis Child 1980;134:19-20.

${ }^{13}$ Burrow GN, ed. Neonatal thyroid screening. New York: Raven Press, 1980.

14 New England Congenital Hypothyroidism Collaborative. Effects of neonatal screening for hypothyroidism: prevention of mental retardation by treatment before clinical manifestations. Lancet 1981 ;ii:1095-8.

(Accepted 25 March 1982)

\title{
Cardiac rhythm abnormalities in patients presenting with transient non-focal neurological symptoms: a diagnostic grey area?
}

\author{
D P DE BONO, C P WARLOW, N M HYMAN
}

\begin{abstract}
Eighty-nine patients attending neurology clinics with transient non-focal neurological symptoms were studied by routine electrocardiography and 24-hour monitoring of the electrocardiogram. In comparison with 109 control subjects there was no significant overall excess of arrhythmias (age-adjusted odds ratio $1 \cdot 7, \chi^{2}=2 \cdot 67$ ) except in the subgroup of patients under the age of 30 (odds ratio $11.6, p<0.05)$. Bradyarrhythmias, but not tachyarrhythmias, were significantly more common in the patients (odds ratio $7 \cdot 4, p<0.001$ ). Since patients can rarely be studied while they are having symptoms a working diagnosis must be based on a balance of probabilities: arrhythmias in young patients, or bradyarrhythmias in any patient, are likely to be clinically relevant. Ambulatory electrocardiographic monitoring contributed to the diagnosis in at least 25 of the patients, Nevertheless, the extent to which further investigations are pursued, and the form of treatment ultimately adopted, must also be influenced by the frequency and severity of the patients' symptoms.
\end{abstract}

\section{Introduction}

The longstanding concept of an association between disturbance of cardiac rhythm and neurological symptoms was revitalised by the introduction of long-term ambulatory electrocardiographic monitoring, ${ }^{12}$ particularly for patients with infrequent or sporadic symptoms. Most reports ${ }^{3-5}$ of cardiac arrhythmias

Edinburgh Royal Infirmary, Edinburgh EH3 9YW

D P DE BONO, MD, MRCP, consultant cardiologist

Radcliffe Infirmary, Oxford OX2 6HE

C P WARLOW, MD, MRCP, clinical reader in neurology

N M HYMAN, MRCP, consultant neurologist detected by this method in patients with transient neurological symptoms have tended either to be anecdotal or to deal with more or less selected populations referred to a cardiac department. Clarke $e t a l^{6}$ cautioned against an uncritical acceptance of the clinical relevance of arrhythmias detected during asymptomatic periods. Nevertheless, there has been increasing demand for investigation in patients of this type, with important implications in terms of cost and the allocation of resources. We have therefore undertaken a case-control study of cardiac arrhythmias using ambulatory monitoring in consecutive patients with transient non-focal neurological symptoms presenting to a neurology service.

\section{Patients and methods}

Eighty-nine patients were referred by their general practitioners over 30 months, and most were examined by NMH or CPW. Patients referred direct to the cardiology service were not included. All the patients had had transient episodes of loss or disturbance of consciousness (giddiness, dizziness, faintness) without focal neurological symptoms. Patients with a clear clinical diagnosis of epilepsy, transient ischaemic attacks, transient global amnesia, labyrinthine vertigo, or migraine were excluded. A total of 109 controls matched for sex and (roughly) for age were selected from outpatients, ambulant inpatients, and doctors, nurses, and physiotherapists. Fifty-seven controls had primary neurological disorders not known to be related to cardiac or cerebrovascular disease-for example, cerebral neoplasm, radiculopathy, and carpal tunnel syndrome; 35 had non-neurological diagnoses such as peptic ulcer, lymphoma, and skin disorders; and 17 were healthy.

Patients and controls were examined by DDEB and subjected to 12-lead electrocardiography (Elema Mingograph, three-channel), $M$ mode echocardiography (SKI Ekoline with Honeywell recorder), and at least one 24-hour period of ambulatory electrocardiographic monitoring (Oxford Instruments, Medilog system). All were encouraged to be up and about during the recording. A modified Marriott CM 1 electrode position was used. Tapes were analysed blind using either Oxford Instruments or Pathfinder equipment with visual monitoring. Some patients had repeat 24-hour recordings or intracardiac electrophysiological studies, or both, according to a standard protocol.? 


\section{Results}

Table I shows the frequency of symptoms in the 89 patients. The controls were slightly older than the patients (the control group had also been used in part in a concurrent study of transient ischaemic

TABLE I-Frequency of symptoms in patients presenting with transient disturbance of non-focal neurological function

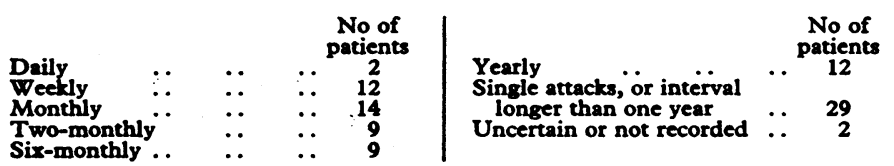

done in 12 patients (the results not being included in the case-control comparison), with useful additional information obtained in one patient who had an episode of prolonged sinus arrest during the second 24-hour recording. From the history, clinical examination, investigations, and response to treatment the patients were finally divided into five diagnostic categories (table III). Twenty-seven patients $(30 \%)$ were thought to have a probable cardiac cause for their symptoms, and these patients were not significantly different from the others in the frequency or duration of their attacks, the occurrence of palpitations, or the observation of pallor or flushing before, during, or after an attack.

The prevalence of structural cardiac defects (such as mitral prolapse), hypertension, and historical or resting electrocardiographic evidence of ischaemic heart disease was not significantly different between the patients and controls (table IV).

TABLE II-Distribution of cardiac conduction and rhythm abnormalities in routine electrocardiogram plus one 24-hour ambulatory recording in patients and controls

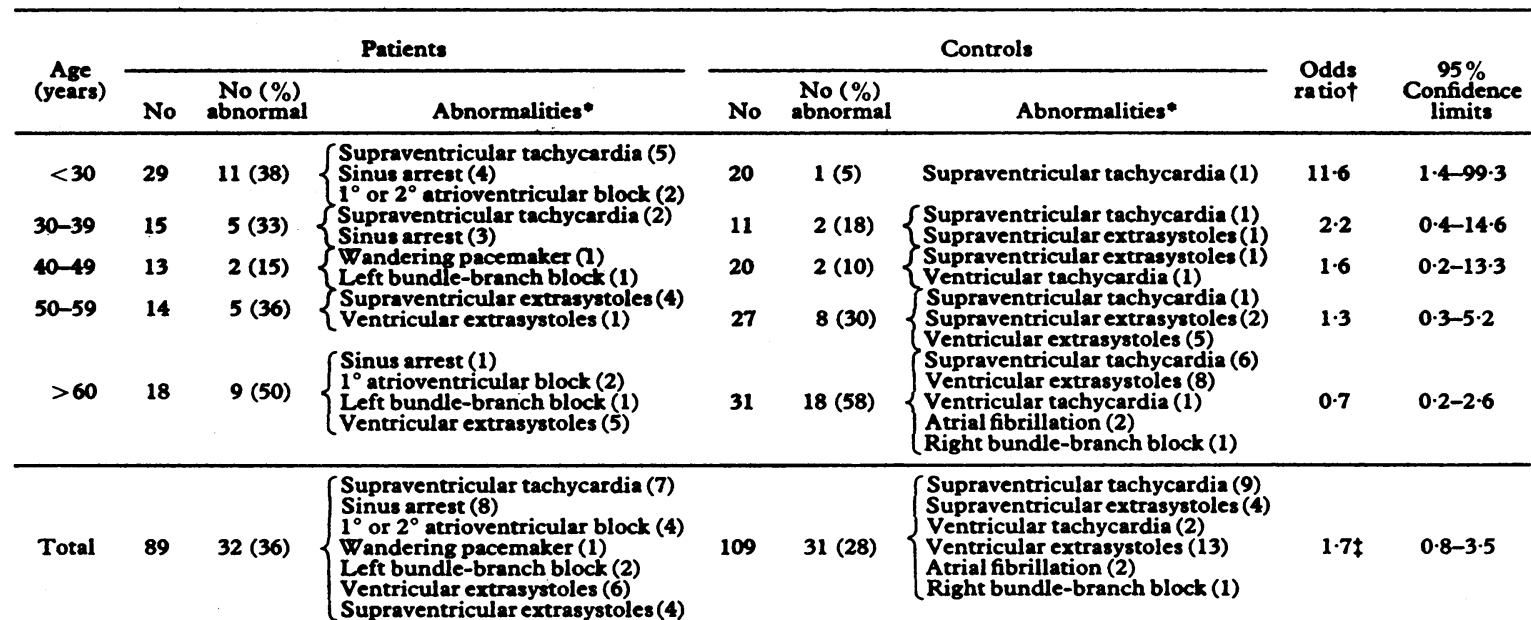

* Sinus arrest defined as either sudden increase in P-P interval to twice or more of preceding value or sinus pause of 1.88 or longer terminated by escape beat. Supraventricular extrasystoles (narrow QRS) defined as such beats occurring more often than 1 per 1000 complexes at any time. such beats occurring more often than 1 per 1000 complexes or in couplets or triplets. Ventricular tachycardia defined as three or more consecutive ventricular extrasystoles. No patient had consistent bradycardia of $60 /$ min or less. Transient sinus bradycardia, particularly at night, was common and not regarded as pathological.

tOdds ratio is odds of a rhythm disturbance in patients divided by odds of a rhythm disturbance in controls.

$\$$ Adjusted for age differences between patients and controls.

attacks) and we therefore adjusted the overall comparison for age (Mantel Haenszel test).

There was no noticeable difference in the prevalence of cardiac arrhythmias between men and women, and their results are considered together. Table II gives the age-specific prevalence of cardiac conduction and rhythm abnormalities detected in a routine 12-lead electrocardiogram and one 24-hour ambulatory recording. The overall prevalence of cardiac arrhythmias was slightly higher in the patients than in the controls (age-adjusted odds ratio 1.7), but this difference was not significant $\left(\chi^{2}=2 \cdot 67\right)$. There was, however, a significant excess of arrhythmias in patients under 30 (odds ratio $11 \cdot 6, \chi^{2}=5 \cdot 28$, $\mathrm{p}<0.05$ ), and the difference between the patients and controls became smaller with increasing age. Bradyarrhythmias or conduction disturbances occurred in 15 of the 89 patients $(17 \%)$ compared with one of the 109 controls (age-adjusted odds ratio $7 \cdot 4,95 \%$ confidence limits $2 \cdot 0-27 \cdot 7, p<0 \cdot 001$ ) but there was no significant difference with regard to tachyarrhythmias ( 17 of the patients $(19 \%)$ compared with 30 $(28 \%)$ of the controls; age-adjusted odds ratio $0.78,95 \%$ confidence limits $0 \cdot 2-1 \cdot 7$ ). There were two other patients who, despite repeatedly normal ambulatory recordings, had abnormalities of atrioventricular conduction and sinus node recovery time during intracardiac electrophysiological studies.

A single 24-hour electrocardiogram was classified as positively diagnostic (symptoms coinciding with a detected arrhythmia) in only three patients and as negatively diagnostic (symptoms coinciding with a normal electrocardiogram) in only four; in the remaining 82 patients the tracing was "non-diagnostic" (no symptoms during the recording). The resting 12-lead electrocardiogram was abnormal in five patients (three with first-degree atrioventricular block, two with left bundle-branch block) and three controls (two in atrial fibrillation, one with right bundle-branch block). Repeat 24-hour recordings were

\section{Discussion}

The prevalence of arrhythmias and the age distribution in our control population were closely similar to other "normal" populations. 8 - Our patients would be expected to have a low prevalence of overt cardiac disease, since those with a history or physical findings suggestive of cardiac disease would have been more likely to be referred direct to the cardiac service and not the neurology service.

It could be predicted from the relative infrequency of symptoms in most patients (table I) that few would have had symptoms during the investigations. The concept of requests for ambulatory electrocardiographic monitoring is that asymptomatic arrhythmias may give clues to the potential occurrence of a major arrhythmia likely to cause symptoms. We found an overall excess of arrhythmias in the patients only in the youngest age group, where there was a particularly low prevalence of abnormality in the controls. In the intermediate age groups there was a lower but similar prevalence of abnormalities in patients and controls, while in the older patients asymptomatic arrhythmias -and particularly extrasystoles and short episodes of tachycardia-were just as or more common in controls than in the patients with transient neurological symptoms. Clearly caution is needed in attributing clinical significance to asymptomatic arrhythmias in elderly patients. In all age groups bradycardias or conduction defects seemed more likely to be of clinical relevance than tachyarrhythmias, and overall there was a significant excess in the patients. 
TABLE III-Final working diagnoses in 89 patients with transient non-focal neurological symptoms

\begin{tabular}{|c|c|c|c|c|}
\hline Category & Definition & $\begin{array}{c}\text { No of } \\
\text { patients }\end{array}$ & $\begin{array}{l}\text { No with documented arrhythmias } \\
\text { (on routine and/or ambulatory } \\
\text { electrocardiography) }\end{array}$ & Individual diagnoses \\
\hline (1) Non-cardiac & $\begin{array}{l}\text { Symptoms later found to be due to } \\
\text { other causes }\end{array}$ & 6 & 2 & $\begin{array}{l}\text { Epilepsy }(1)^{*} ; \text { postural hypotension (1); } \\
\text { "unknown" but normal recording } \\
\text { during symptoms (4) }\end{array}$ \\
\hline $\begin{array}{l}\text { (2) Probably non-cardiac } \\
\text { (3) Unlikely cardiac }\end{array}$ & $\begin{array}{l}\text { Potential other cause for symptoms } \\
\text { No clinical or investigative features to } \\
\text { suggest cardiac (or other) cause }\end{array}$ & $\begin{array}{l}18 \\
11\end{array}$ & $\begin{array}{l}2 \\
0\end{array}$ & (1) \\
\hline (4) Possibly cardiac & $\begin{array}{l}\text { Clinical features suggest cardiac cause, } \\
\text { but no strong objective evidence }\end{array}$ & 27 & $\begin{array}{l}16 \text { (infrequent ventricular extrasystoles } \\
\text { and supraventricular extrasystoles) }\end{array}$ & \\
\hline (5) Probably cardiac & $\begin{array}{l}\text { Cardiac cause likely on basis of history, } \\
\text { investigations, and response to } \\
\text { treatment }\end{array}$ & 27 & 25 & $\begin{array}{l}\text { Sick-sinus syndrome/vagal overactivity } \\
\text { (12); carotid sinus syndrome }(1) ; \\
\text { sarcoid heart block }(1) ; \text { other heart } \\
\text { block (1); supraventricular } \\
\text { tachycardia (7); ventricular } \\
\text { arrhythmias (5) }\end{array}$ \\
\hline
\end{tabular}

*Epilepsy became diagnosis some months after patient was included in study.

TABLE IV-Prevalence of structural cardiac defects (mitral leaflet prolapse etc), hypertension, and ischaemic heart disease

\begin{tabular}{lcccc}
\hline & $\begin{array}{c}\text { Structural } \\
\text { defect }\end{array}$ & Hypertension & $\begin{array}{c}\text { Ischaemic } \\
\text { heart } \\
\text { disease }\end{array}$ & $\begin{array}{c}\text { No } \\
\text { studied }\end{array}$ \\
\hline $\begin{array}{l}\text { No }(\%) \text { of patients } \\
\text { No }(\%) \text { of controls }\end{array}$ & $\begin{array}{ll}23^{*}(26) \\
18(16)\end{array}$ & $6(6)$ & $6(7)$ & 89 \\
\hline
\end{tabular}

*Age-adjusted odds ratio $1 \cdot 8,95 \%$ confidence limits $0 \cdot 86-3 \cdot 76, \chi^{2}=2 \cdot 53$.

The management of individual patients with a tachycardia will most likely be a therapeutic trial of one or more antiarrhythmic drugs. If the suspected abnormality is a bradycardia the choice is far more onerous-namely, whether or not to implant a cardiac pacemaker. In young patients transient atrioventricular block or abnormalities of sinus node function may result from excessive vagal activity rather than degenerative disease. ${ }^{10}$ Vasovagal syncope, which usually includes both a cardioinhibitory and a vasodepressor component, is traditionally regarded as a benign disorder, but in a few cases, and particularly when prolonged asytole occurs, it may be life threatening. ${ }^{11} \mathrm{Six}$ patients in this series who had intracardiac electrophysiological studies on account of severe and persistent symptoms were given atropine: four showed improved atrioventricular conduction and three a "normalised" prolonged sinus node recovery time. Though anticholinergic drugs would theoretically be attractive, we find them to be poorly tolerated. Five of these patients subsequently received pacemakers, with relief of their symptoms. Overall, 11 patients $(12 \%)$ received permanent pacemakers, with complete relief of symptoms in eight, partial relief in two, and no relief in one (who had not had an electrophysiological study). In practice the decision to implant a pacemaker in patients with transient abnormalities of sinus or atrioventricular node function is likely to be guided principally by the severity and persistence of the symptoms. There is little evidence that survival is improved by pacing in such patients with absent or minimal symptoms. ${ }^{12}$

The proportion of diagnostic recordings (and, of course, number of irrelevant arrhythmias) would no doubt have been higher if we had routinely recorded for 48 hours or more rather than 24 hours, but the implications in time and cost would be considerable. It is probably justifiable to reserve repeat recordings for patients with particularly severe or persistent symptoms. We found that traditional clinical features were unhelpful in predicting which patients would have abnormalities on ambulatory electrocardiographic recordings.

Because there is no precise boundary between normality and abnormality in ambulatory recordings made in the absence of symptoms we cannot say exactly how much useful additional information was provided by ambulatory monitoring of our patients; to do this we should have needed an independent means of confirming the diagnosis. Nevertheless, of 27 patients thought eventually to have a "probably cardiac" cause for their symptoms, five had conduction or rhythm abnormalities apparent in the 12-lead electrocardiogram, another 20 had abnormalities detected on ambulatory monitoring, and two had possible abnormalities only detected during an electrophysiological study. If the four patients in whom symptoms occurred in the absence of an electrocardiographic abnormality are added, ambulatory monitoring contributed to a working diagnosis in at least 24 of our 89 patients $(27 \%)$. There is thus justification for including at least one period of ambulatory monitoring in the investigation of all patients presenting with transient non-focal neurological symptoms. Any arrhythmia detected must, however, be interpreted in the light of the frequency and severity of the clinical symptoms, whether the abnormality is a tachycardia or bradycardia, and of a knowledge of the prevalence of the arrhythmia in a control population of similar age.

We thank Dr Klim McPherson and Dr Robert Haile for statistical and epidemiological advice, Miss Rosie Phillips for the electrocardiographic monitoring, and the Oxford Regional Health Authority (Teaching) for a grant from the locally organised research fund scheme.

\section{References}

${ }^{1}$ Gilson JS, Holter NJ, Glasscock WR. Clinical observations using Electrocardiocorder AVSEP continuous electrocardiographic system. $\mathrm{Am} f$ Cardiol $1964 ; 14: 204-17$.

${ }^{2}$ Crooke BRM, Cashman PMM, Stott ED, Raftery EB. Tape monitoring of the electrocardiogram in ambulant patients with sinoatrial disease. Br Heart 7 1973;35:1009-13.

${ }^{3}$ Schott GD McLeod AA, Jewitt DE. Cardiac arrhythmias that masquerade as epilepsy. $\mathrm{Br} \mathrm{Med} \mathcal{F} 1977$; : 1454-7.

${ }^{4}$ Jonas S, Klein I, Dimant J. Importance of Holter monitoring in patients with periodic cerebral symptoms. Ann Neurol 1977;i:476-84.

5 Luxon LM, Crowther A, Harrison MJG, Coltart DJ. A controlled study of 24 hour ambulatory electrocardiographic monitoring in patients with transient neurological symptoms. F Neurol Neurosurg Psychiatry 1980; $43: 37-41$.

${ }^{6}$ Clarke JM, Hamer J, Shelton JR, Taylor S, Venning GR. The rhythm of the normal human heart. Lancet 1976;ii:508-12.

7 Curry PVL. Fundamental of arrhythmias: modern methods of investigation. In: Krikler DM, Goodwin JF, eds. Cardiac arrhythmias: the modern electrophysiological approach. London: W B Saunders, 1975 39-80.

${ }^{8}$ Brodsky $M$, Wu D, Denes $\mathrm{P}$, Kanakis C, Rosen KM. Arrhythmias documented by 24 hour continuous electrocardiographic monitoring in 50 male medical students without apparent heart disease. Am $\mathcal{F}$ Cardiol 1977;39:390-5.

${ }^{9}$ Verbaan CJ, Pool J, Van Wanrooy J. Incidence of cardiac arrhythmias in a presumed healthy population. In: Stott FD, Raftery EB, Sleight $\mathrm{P}$ Goulding L, eds. IS AM 1977. London: Academic Press, 1978:1-7.

10 Caralis DG, Varghese PJ. Familial sinoatrial node dysfunction. Increased vagal tone a possible aetiology. Br Heart $\mathcal{F} 1976 ; 38: 951-6$.

11 Taggart P, Hedworth-Whitty R, Carruthers M, Gordon PD. Observations on electrocardiogram and plasma catecholamines during dental procedures: the forgotten vagus. $B r M e d \mathcal{F} 1976$;ii :787-9.

12 Shaw DB, Holman RR, Gowers JI. Survival in sinoatrial disorder (sicksinus syndrome). $\mathrm{Br} \mathrm{Med} \mathcal{F} 1980 ; 280: 139-41$.

(Accepted 18 March 1982) 